Review

\title{
Trends of Pesticide Exposure and Related Cases in the Philippines
}

\author{
Jinky Leilanie Lu ${ }^{1}$, Katherine Z. Cosca ${ }^{2}$ and Jocelyn Del Mundo ${ }^{3}$ \\ ${ }^{1}$ National Institutes of Health, University of the Philippines Manila, Manila, Philippines \\ ${ }^{2}$ The Medical City, Philippines, Metro Manila, Philippines \\ ${ }^{3}$ College of Arts and Sciences, University of the Philippines Manila, Manila, Philippines
}

\begin{abstract}
The study aims to provide a comprehensive trend of pesticide poisoning cases in the Philippines as well as pesticide exposures, and risk factors related to the adverse effects of pesticide. Records were gathered from the National Poison Control and Management Center (NPCMC), the Philippine General Hospital, De La Salle Medical Center, and other hospitals, and reviewed research studies conducted in the Philippines. Based on hospital surveys, the number of pesticide cases as well as mortality trends have been increasing. Studies from 2006 to 2010 showed that human health especially those of the farmers is at risk due to pesticide exposure. Illnesses and symptoms such as headache, skin abnormalities, fatigue, fever, and weaknesses were the common health complaints experienced by the farmers as reported in the research studies. Moreover, the studies showed risk factors to pesticide exposure, work practices, and pesticide residues in environmental media that could be contributory to pesticide poisoning cases. Government agencies should intensify their surveillance and regulation on both household and agricultural pesticides. The state of pesticide-related illnesses mirrors the poor safety practices among farmers as well as lack of necessary supervision from the government agencies.
\end{abstract}

Key words: pesticide exposures and risk factors, pesticide poisoning cases, pesticide residues, agriculture, occupational health and safety

(J Rural Med 2010; 5(2): 153-164)

\section{Introduction}

Pesticides are widely used by developing countries such as the Philippines for agricultural purposes. However, pesticide poisoning is still one of the global health problems.

Correspondence to: Jinky Leilanie Lu

National Institutes of Health, University of the Philippines Manila,

NIH Bldg, P. Gil Street, Ermita, Manila, Philippines 1100

E-mail:jinky_lu@yahoo.com
It is estimated that about 5 million people die every year as a result of intentional, accidental, and occupational exposures worldwide ${ }^{1)}$.

Pesticides are primarily used in agriculture. Agriculture is one of the contributors to the Gross Domestic Product (GDP) in the Philippines. In 2005, the Gross Domestic Product (GDP) of the country was estimated to be US $\$ 451.3$ billion, or US $\$ 5,100$ per capita ${ }^{2}$. The largest contributors to the growth of GDP came from the services (52.8\%) and industrial sectors $(31.8 \%)$ whereas agriculture accounted for $15.3 \%^{3}$. In 2008, the Bureau of Agricultural Statistics reported that the country's Gross National Product grew by 6.17 percent, and the Gross Domestic Product expanded by 3.84 percent compared to the previous year. Agriculture and fishery sectors, which contributed 18 percent to the Gross Domestic Product, gave a 3.23 percent growth. The employment rate was $92.6 \%$ or a total of 34.09 million employed persons in 2008. About 12.03 million persons were employed in the agriculture sector, and they represented 35 percent of the country's labour force. The major agricultural products in 2008 were rice, corn, coconuts, and bananas (see Table 1) as well as livestocks and poultry. In 2005 , crops accounted $46.4 \%$ of the value of all agricultural production, while livestock and poultry accounted only $28.8 \%$, and fishing at $24.9 \%{ }^{2}$.

Table 2 shows the list of the most commonly used pesticides in the Philippines. Based on surveys, these pesticides are used by farmers in amounts ranging from $2-5$ $\mathrm{ml}$ per 16 liters of water for liquid pesticides and $3-5 \mathrm{~g}$ per 16 liters for pesticides in solid form ${ }^{4}$. For every application, their loads can range up to $15-20$ per 500 square meters to 1,000 square meters.

Pesticides are also used in and around the home to get rid of the household pests such as cockroaches, mosquitoes, termites, ants, rats, and germs. Table 3 shows the list of known household pesticides in the country. In the United 
Table 1 Agricultural outputs in the Philippines per major crop (2009)

\begin{tabular}{lll}
\hline \multicolumn{1}{c}{ Agricultural crop } & \multicolumn{1}{c}{ Area } & \multicolumn{1}{c}{ Production (metric tons) } \\
\hline Vegetables & Benguet & Broccoli: 2,685 \\
& & Cabbage: 124,712 \\
& & Carrots: 68,328 \\
& & Cauliflower: 10,559 \\
Rice/Palay Production & Central Luzon & Lettuce: 3,577 \\
Banana & Davao Region & $16,266,417$ \\
Mango & Ilocos Region & $9,013,186$ \\
Sugarcane & Western Visayas & 771,441 \\
Corn & Cagayan Valley & $22,932,819$ \\
Coconut & Davao Region & $7,034,033$ \\
Pineapple & Northern Mindanao and & $15,667,565$ \\
& SOCCSKSARGEN (South Cotabato, & $2,198,497$ \\
& Sultan Kudarat, Saranggani and & \\
\hline
\end{tabular}

Source: Bureau of Agricultural Statistics, 20094).

Table 2 List of commonly used pesticides in the Philippines

\begin{tabular}{lc}
$\begin{array}{c}\text { Most commonly used pesticide } \\
\text { in the Philippines }\end{array}$ & $\begin{array}{c}\text { Amount used/ Pesos (Annual) } \\
\text { Liquid-liter/pesos; solid-kilogram/pesos }\end{array}$ \\
\hline Dithane (Fungicide) & 464.17 \\
Mancozeb (Fungicide) & 426.21 \\
Funguran (Fungicide) & 704.72 \\
Cypermethrin (Insecticide) & 320 \\
Decis (Insecticide) & $1,108.33$ \\
Malathion (Insecticide) & 311.67 \\
Clear out (Weedicide) & 460.83 \\
Round-up (Weedicide) & 500 \\
\hline
\end{tabular}

Source: Bureau of Agricultural Statistics, 20104).

Table 3 List of household pesticides

\begin{tabular}{llll}
\hline Brand name & \multicolumn{1}{c}{ Generic name } & Classification & \multicolumn{1}{c}{ Company } \\
\hline Baygon total insect killer & Transfluthrin and cyfluthrin & Pyrethroid & Bayer Phils, Inc. \\
Racumin ready made bait & Coumatetralyl & Rodenticide & Bayer Phils, Inc. \\
Raid germkill insect killer liquid & Propoxur + neopynamin & Carbamate & S.C. Johnson \& Son, Inc \\
KISS napthalene balls & Napthalene & & D' World 2000 Enterprise \\
OFF! Classic insect repellant lotion & DEET & SC Johnsons \& Sons, Inc. \\
\hline
\end{tabular}

Source: Fertilizer and Pesticide Authority, 2002 ${ }^{6}$.

States, about $85 \%$ to $90 \%$ of the households used pesticides, and children were vulnerable to exposure to household pesticides. Young children may be exposed in various ways such as inhalation, absorption through skin contact, ingestion during food consumption or accidental ingestion of the pesticide itself. Moreover, children are at higher risk of exposure than adults since per pound of body weight, children breathe more, eat more, and have more rapid 
metabolism than adults ${ }^{5}$.

In the Philippines, the government agency that regulates the use of pesticides is the Fertilizer and Pesticide Authority (FPA). This agency is primarily responsible for the registration of pesticide active ingredients and formulated products, and licensing of all pesticide handlers and pest control operators, and agro-medical training programs. Unfortunately, the policies of FPA are not well disseminated and followed by the public such that restricted and banned pesticides are still found present in the foods. Farmers still do not have enough knowledge regarding safe handling of pesticides; and there is still inadequate number of trained rural health workers. It is therefore suggested that FPA should be given sufficient manpower and resources to enable it to do its mandate ${ }^{7}$.

\section{Methods and Materials}

The data for this study were gathered from reviews of literature and journals on pesticides, pesticide use, pesticide poisoning and related concerns. Data were taken from at the Department of Health, the Philippine General Hospital, and other hospitals. Moreover, records in agricultural and related agencies like the Philippine Council for Agriculture, Forestry and Natural Resources Research and Development, and Philippine Council for Industry and Energy Research Development - Department of Science and Technology, Department of Health, Department of Agriculture, Bureau of Agricultural Statistics, Bureau of Soils and Water Management, and the University of the Philippines, Los Banos were also gathered and included in this review. Exhaustive data reviews, and collection of records were undertaken in order to make comprehensive data trends of pesticide poisoning cases in the country. Other studies conducted by researchers and health practicioners in the past filled in missing information on pesticide poisoning.

Data and reports were also taken from National Poison Control and Information or now known as National Poison Management and Control Center (NPCMC). This is the first poison control center in the Philippines Manila in partnership with the Department of Health. It is housed at the Philippine General Hospital, University of the Philippines. This center was established as a response to the increasing incidence of poisoning due to improper and rampant use of pesticides in the country. The center focuses on the management of acute poisoning cases.

Analysis for the data was done for the annual data records on pesticide poisoning cases of hospital surveys, as well as comparison of the results of the research studies in the different years and geographical locations were done.

There is a large dearth of data on pesticide poisoning in the Philippines. The latest record is done by the National Poison Control and Management Center. However, the data are limited, and pesticide is mostly categorized as mixed pesticide. There are no further categorizations or classifications per socio-demographics, regional profiling, and trending. The Department of Health also does not keep a record of pesticide poisoning cases in the Philippines. This posed as a challenge and limitation in this review of pesticide exposure and poisoning in the Philippines.

\section{Results and Discussion}

Pesticide poisoning has become an increasing health problem in the Philippines. Based on the records of the National Poison Control Management Center (NPCMC) ${ }^{8)}$, mixed pesticide had been in the top 10 poisons recorded from 2004-2009 (see Figures 1-7). In the year 2004, of the 260 poison cases, 17 poisoning cases were recorded due to mixed pesticides (Figure 1). In the year 2005, 20 of the 295 cases were due to mixed pesticide (Figure 2). In 2006, of the 1216 cases of poisons, there were 118 pesticide poisoning cases (Figure 3). Mixed pesticides accounted for 104 of the 3,620 poison cases in 2007 (Figure 4), and 209 of the 3931 cases in $2008^{8}$. In 2009, pesticide ranked third with 164 cases (Figure 6).

Shown in Figure 7 is the trend of mixed pesticide poisoning cases recorded from 2004 to 2009 . For a total of poisoning cases for six years from 2004 to 2009, pesticide poisoning ranks sixth. This means that mixed pesticides have become part of the main causes of poisoning cases in the Philippines. Other studies have reported poisoning cases and their relationship with increased mortality rates ${ }^{9-11)}$. In the study of Loevensohn ${ }^{11}$, he noted that there is widespread use of pesticides by farmers in Central Luzon in the Philippines. Briones also reported that, from 1980 to $1988,15 \%$ of an average of 503 cases had died of pesticide poisoning every year ${ }^{12)}$.

\section{Hospital Surveys on Pesticide Poisoning Cases}

Over the period 1980-1987, hospitals in the Philippines under the jurisdiction of the Department of Health recorded 4,031 cases of acute pesticide poisoning and 603 cases resulted in death ${ }^{13)}$. At JP Rizal Memorial Medical Center and DLSU-Medical Center, from January, 1985 to December, 1987, 49 cases of poisoning from all causes were reviewed. Twelve cases were related to pesticide intoxication $^{14)}$. At the Philippine General Hospital, there were 78 admissions out of a total of 1,112 poisoning cases seen from April 2000-March 2001. In 2002, pesticide poisoning ranked second among the 2,848 poisoning cases referred to the poison information service ${ }^{15)}$. Thirty two per- 


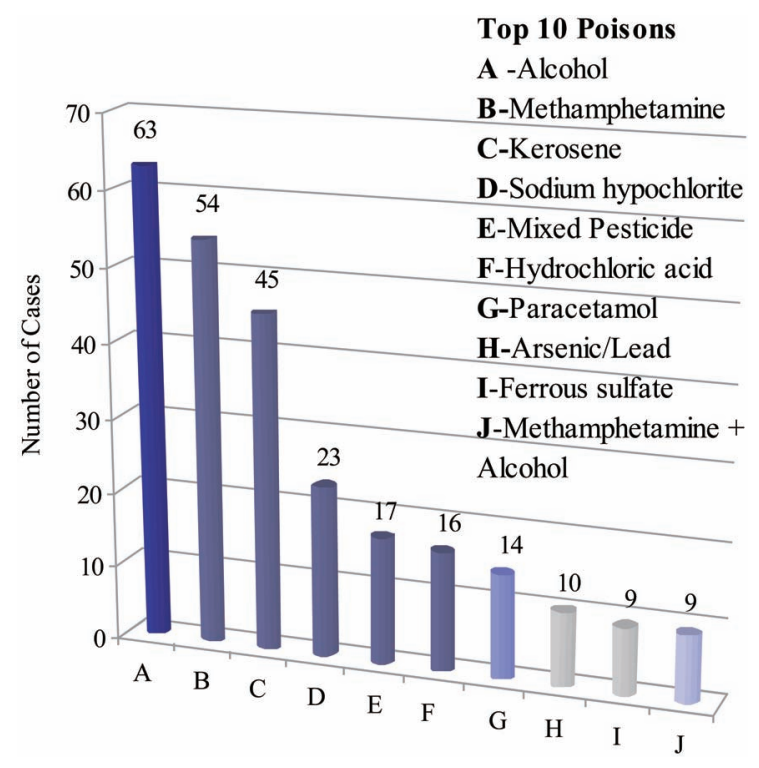

Figure 1 Frequency of top ten poisons including pesticide poisoning cases, $2004(\mathrm{~N}=260)$. Source: NPCMC, 2004 ${ }^{8}$.

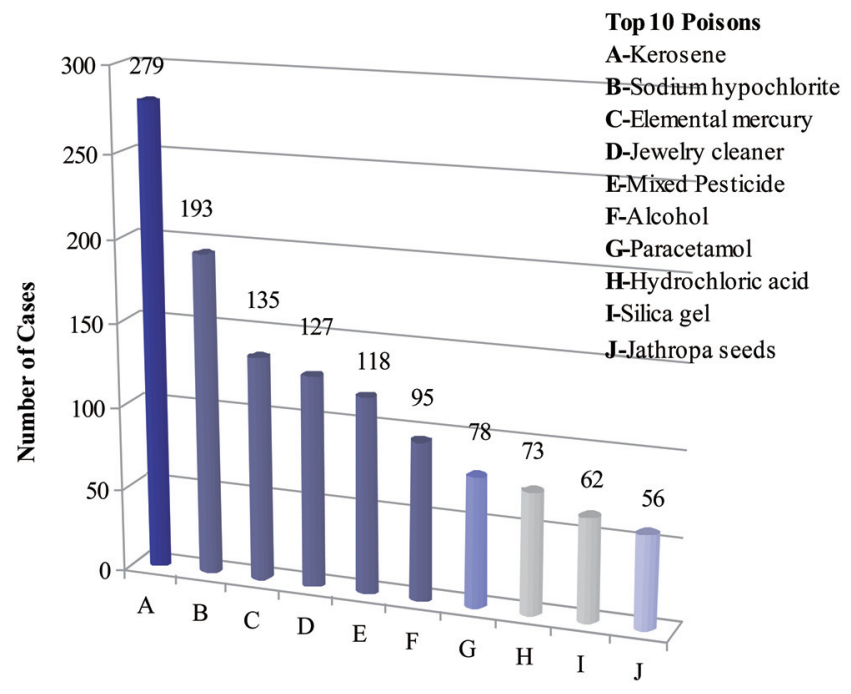

Figure 3 Frequency of top ten poisons including pesticide poisoning cases, $2006(\mathrm{~N}=1216)$. Source: NPCMC, $2006^{8)}$.

cent of such cases were secondary to mixed household pesticides. In Benguet General Hospital in northern Philippines, there had been increasing reports of pesticide poisoning among agricultural workers from 1987 to 1989. Approximately $30 \%$ of these were due to accidental poisoning ${ }^{16)}$. Moreover, farm-work related diseases such as dermal and allergic disorders were noted ${ }^{17)}$.

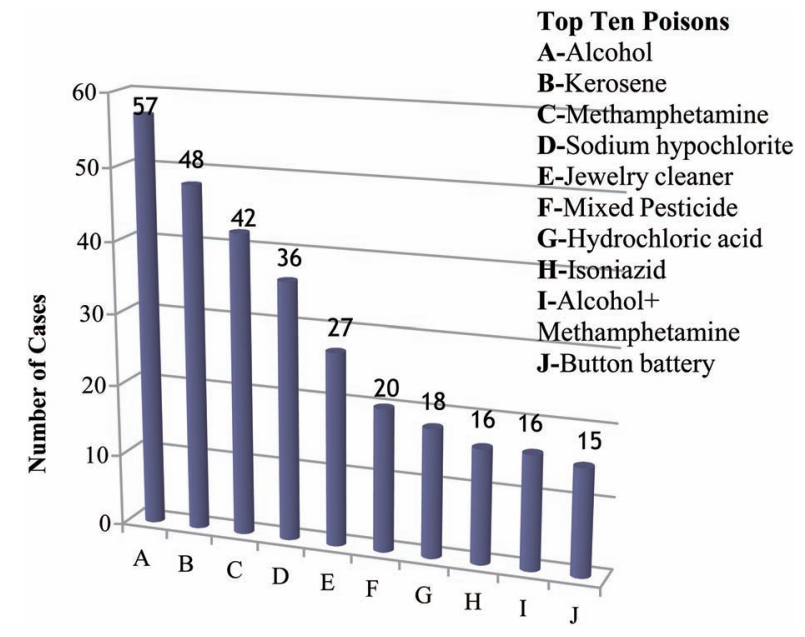

Figure 2 Frequency of top ten poisons including pesticide poisoning cases, $2005(\mathrm{~N}=295)$. Source: NPCMC, $2005^{8)}$.

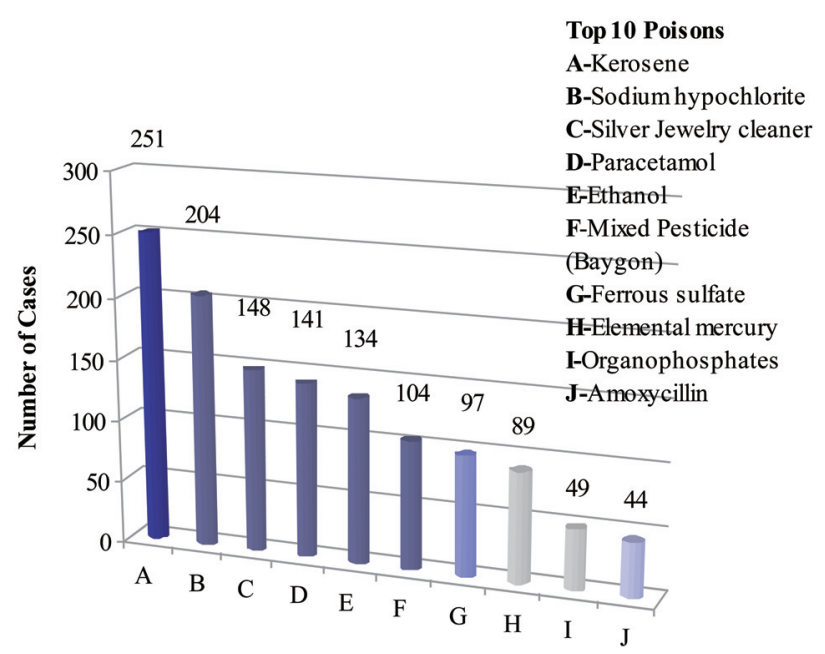

Figure 4 Frequency of top ten poisons including pesticide poisoning cases, $2007(\mathrm{~N}=3,620)$. Source: NPCMC, $2007^{8)}$.

In the study conducted by the National Poison Control and Information Service (NPCIS), there were 2,346 poisoning cases reported from 1986 to 1990 involving 38 hospitals in the National Capital Region. The incidence was 27.6/100 population with a case fatality rate of 1.4. From 1992 to 1994, 2,587 poisoning cases were recorded involving 7 hospitals in the National Capital Region with an incidence of 


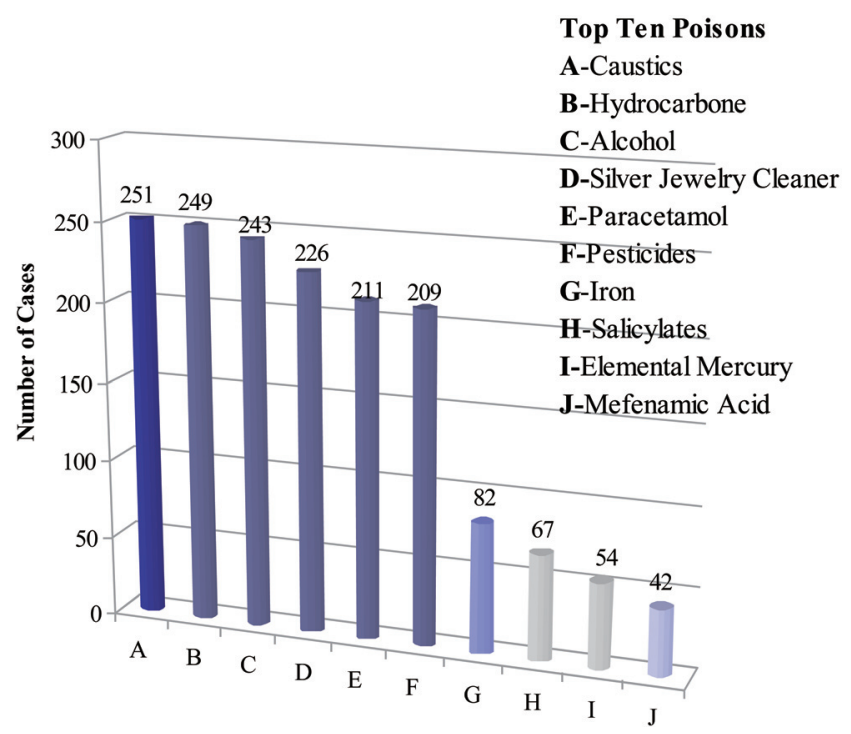

Figure 5 Frequency of top ten poisons including pesticide poisoning cases, $2008(\mathrm{~N}=3,931)$. Source: NPCMC, $2008^{8)}$.

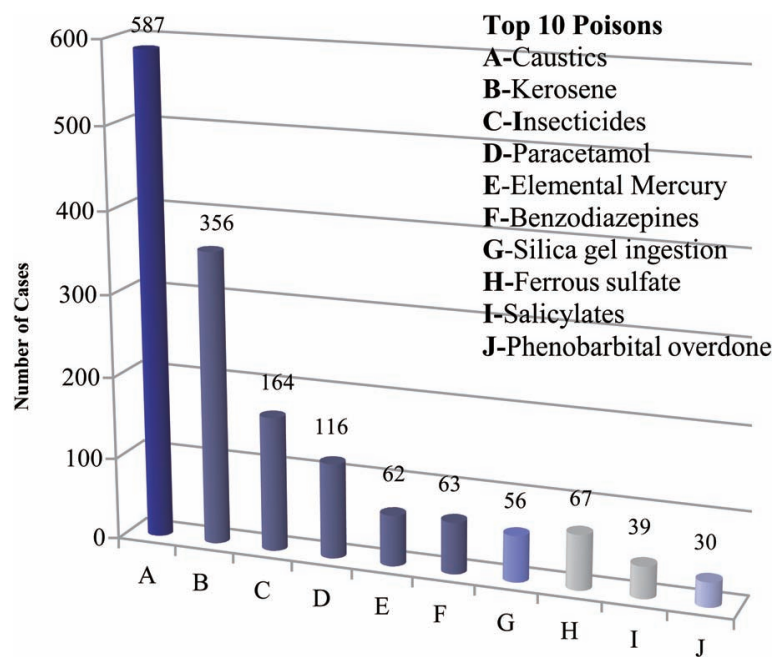

Figure 6 Frequency of top ten poisons including pesticide poisoning cases, $2009(\mathrm{~N}=1,526)$. Source: NPCMC, $2009^{8)}$.

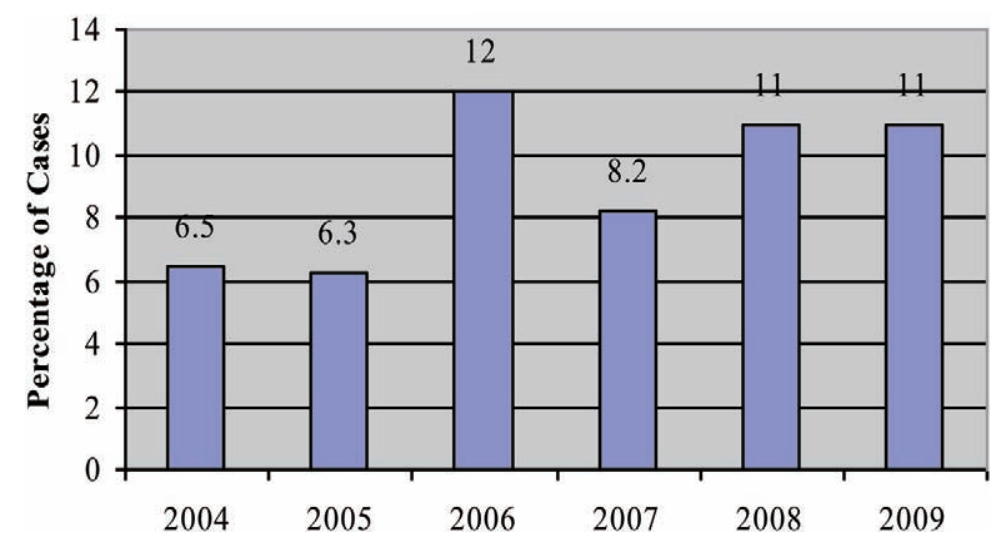

Figure 7 Percentage distribution of mixed pesticide poisoning cases from 2004 to 2009. Source: NPCMC ${ }^{8}$.

$30.4 / 100$ and a case fatality rate of 2.7. In 2000, the NPCIS's in-patient statistics recorded a total of 956 patients of pesticide poisoning cases. In April 2000 and May 2001, there were 273 pesticide poisoning cases recorded by the NPCIS, most commonly due to ingestion, and approximately 16 cases of death. From 2000 to 2001 data gathered through the epidemiologic study of NPCIS revealed a total of 328 pesticide poisoning cases admitted from a total of 789 poisoning cases in 34 hospitals $^{8)}$. Moreover, Dioquino reported a total of 273 cases of poisoning and 16 deaths over the year ${ }^{17}$. Majority were due to severe cases of organophosphate or organochlorine poisoning.

\section{Regional Records on Pesticide Poisoning Cases in the Philippines}

In Davao Del Norte which is in the southern part of Luzon Island in the Philippines, a case report showed pesticide poisoning among residents due to the chemical leak of ethotrop. This chemical is contained in a nematocide Mocap used to spray in banana plantation in the town of Braulio Dujali, Davao del Norte. Ethotrop is a chemical ingredient that severely affects the functioning of the nervous system. This toxin causes tremors, nausea and weakness at low exposure, and paralysis and death on exposure to high doses, 
according to the Pesticide Action Network. There were at least 79 people affected by the said chemical leak. Most of them were school children and at least 30 students passed out while they were gathering for the flag ceremony. The victims inhaled the toxic chemical fumes after pesticide application in the plantation ${ }^{18)}$.

In Bohol Province located in the southern part of Luzon in the Philippines, a mass pesticide poisoning case among children was reported on March 2005 due to the chemical carbamate commonly used as household and agricultural pesticides. The victims ate cassava contaminated by carbamate $^{19)}$. This is a case of unsafe pesticide storage. The pesticide was mistaken for flour that caused the food poisoning of more than 100 children resulting in 27 deaths $^{20)}$.

In a study conducted among the farmers in Nueva Ecija in northern Philippines, most of the respondents interviewed reported that they had felt some symptoms during or after pesticide application. These symptoms were headache, dizziness, and vomiting ${ }^{21)}$.

In Benguet province which is the vegetable capital of the Philippines and located in the northeastern part of the Philippines, 2,000 vegetable farmers were shown in hospital records to have common complaints of allergic reactions both in the skin and the eyes, abdominal pain, dizziness, chest pain, headache and nose bleeding ${ }^{22)}$. Based on a study ${ }^{23)}$, the full-time farmers experienced more abnormal health findings compared to the part-time farmers.

In a consolidated study conducted by the Pesticide Action Network Asia and the Pacific in Asian countries targeting Digos City in Davao Del Sur which is located in Mindanao island of southern Philippines, adverse health symptoms were shown to be associated with pesticide exposure. Among the farmers interviewed, the most prevalent symptoms were headache (81\%), dizziness (79\%), excessive sweating (3\%), excessive salivation (1\%), blurred vision, and narrowed pupils ${ }^{24)}$.

In some studies, pesticides identified in human tissues were DDT (dichlorodiphenyltrichloroethane), and its metabolites DDE (dichlorodiphenyltrichloroethylene) aldrin, dieldrin and lindane ${ }^{25)}$. Cases of such were reported in Laguna province located in the southern part of Luzon Island. Human milk was also found to contain DDT among women residents in a farming community in Laguna, Philippines $^{12)}$.

\section{Pesticide Poisoning Cases according to Types}

Mixed pesticides are usually categorized as organophosphates, carbamates, pyrethroid, and organochlorines. Organophosphate pesticides are the most popular pesticides used in agriculture ${ }^{26)}$. Most organophosphates are well absorbed by the skin, oral mucous membranes, conjunctiva and gastrointestinal and respiratory routes ${ }^{27)}$. One type of organophosphate is chlorpyrifos. Chlorpyrifos is an organophosphorus anticholinesterase insecticide. Organophosphate intoxication can induce symptoms such as miosis, urination, diarrhea, diaphoresis, lacrimation, excitation of central nervous system, salivation, and consciousness disturbance ${ }^{28)}$. Carbamates such as Carbaryl (SEVIN) and carbofuran (FURADAN) can cause cancer. Some carbamates, such as carbofuran (FURADAN), have been shown to cause birth defects or reproduction ${ }^{29)}$. Organophosphorus and carbamate pesticides are acetylcholinesterase-inhibiting pesticides ${ }^{30}$. Pyrethroids are a group of man-made pesticides that are also used in agriculture. Persons who apply pyrethroids and are accidentally exposed to very large amounts may experience dizziness, headache, nausea and diarrhea ${ }^{31}$. Organochlorine is another pesticide widely used in the agriculture. One type of which is endosulfan which is rapidly absorbed following ingestion, inhalation, or skin exposure. Symptoms occur rapidly following exposure with central nervous system toxicity ${ }^{32)}$.

In the Philippines, the widely used insecticides are carbofuran, endrin, parathion, and monocrotophos, which are all classified by the World Health Organization as extremely or highly hazardous ${ }^{33)}$.

A local study in 2002 showed that insecticides accounted for $71.3 \%$ of the poisoning incidents followed by herbicides at $10.2 \%$. Of the pesticides, pyrethroids accounted for $29.3 \%$, and organophosphates for $22 \%$. Some of the most common pesticides included cypermethrin, malathion, carbofuran, combination cyfluthrin, dichlorvos and propoxur and deltamethrin ${ }^{34)}$.

In the reported poisoning cases in JP Rizal Memorial Medical Center (1985-1987) ${ }^{35)}$, the most common types of pesticides belonged to the organophosphate group of insecticides ( 9 cases), followed by the carbamate group and organochlorine insecticides with 1 case each.

In the Philippine General Hospital which is the largest tertiary and government hospital in the Philippines (2000$2001)^{15)}$, the most commonly encountered pesticides were mixed pesticides $(39 \%)$ containing organophosphates, carbamates and pyrethroids followed by rodenticides (15\%). Majority (62.8\%) presented with minor signs and symptoms of poisoning. Mortality rate was $2.6 \%$. Shown in Figures 17 above, pyrethroids registered the highest number of reported cases of poisoning from 2008-2009.

Based on an epidemiologic study in $2000-2001^{1)}$, the commonly encountered pesticides were pyrethroids (27.2\%), organophosphates $(18.0 \%)$, carbamates $(9.5 \%)$, mixed pesticides $(7.9 \%)$ and chlorophenoxy compounds $(4.0 \%)$. 
Mortality rate was 5.8\% with organochlorine poisoning having the highest case fatality rate $(22.2 \%)^{36}$.

In a study in farming areas of Benguet in 2010 $0^{37)}$, positive results of pesticide residues were obtained in water and soil samples. Of the 78 soil samples, 34 were found to be positive with pesticide residues and of the 49 water samples, 1 sample was found to be positive with pesticide chlorpyrifos..Chlorpyrifos gave a concentration of $0.07 \mathrm{mg} / \mathrm{L}$. In soil samples, the specific residue types were endosulfan sulfate, profenofos, chlorothalonil, T endosulfan, chlorpyrifos, cypermerthrin, and cyhalothrin. The most prevalent types of pesticide in all municipalities were endosulfan sulfate and chlorpyrifos $(17.7 \%)$, followed by profenofos $(8.9 \%)$, cyhalothrin $(5.1 \%)$, cypermethrin $(3.8 \%)$, technical (t) endosulfan $(0.25 \%)$, and then chlorothalonil $(0.13 \%)$. As for pesticide concentration, the most significant pesticide with the highest concentration was t-endosulfan, with a mean concentration of $0.025 \mathrm{mg} / \mathrm{kg}$, followed by endosulfan sulfate $(0.015 \mathrm{mg} / \mathrm{kg})$, chlorpyrifos $(0.01 \mathrm{mg} / \mathrm{kg})$, profenofos $(0.003 \mathrm{mg} / \mathrm{kg})$, chlorothalonil, cypermethrin, and cylohathrin (all at $0.002 \mathrm{mg} / \mathrm{kg}$ ). The samples were positive for cyhalothrin $(5.1 \%$ of soil samples, at a concentration of $0.002 \mathrm{mg} / \mathrm{kg}$ ), and cypermethrin $(3.8 \%$, at $0.002 \mathrm{mg} / \mathrm{kg})$. Chlorpyrifos was found only in soil, and not in water samples. Soil samples were positive for chlorothalonil $(0.13 \%$ of soil samples, at a concentration of $0.002 \mathrm{mg} / \mathrm{kg}$ ). Chlorothalonil is a chloronitrile which is a broad-spectrum OC fungicide and it is degraded more rapidly at higher temperatures and when soil moisture is increased. It has a low water solubility, $0.6 \mathrm{mg} / \mathrm{L}$, at 25 degrees Celsius. There was no water sample with chlorothalonil because of its low water solubility. Chlorpyrifos, which is an organophosphate, was found in $27.4 \%$ of soil samples at $0.01 \mathrm{mg} / \mathrm{kg}$ concentration. It was also found in one water sample at $0.07 \mathrm{mg} / \mathrm{L}$, which is above the threshold limit value for both acute and chronic effects on aquatic and marine life ${ }^{37)}$.

Meanwhile, Rother reported in his study that highlytoxic pesticides, such as aldicarb, methamidophos, and chlorpyrifos, are easily available in informal markets. Plasma cypermethrin, endosulfan, imidacloprid, thiodicarb, carbofuran, and methamidophos levels were found in his study to be higher than allowable daily intake ${ }^{38)}$.

In one study of $\mathrm{Lu}^{23)}$, pyrethroids $(71.1 \%, 73 \%)$ were used by majority of the full- time and part- time farmers. For the full-time farmers, this was followed by organophosphates $(67.8 \%)$ and carbamates $(57 \%)$. For the part-time farmers, carbamate (48\%) was the second most commonly used. Organophopshate was the least used pesticide (31\%). Other pesticides used by both groups included organochlorides and nitrites (Table 2). Both groups were similar in terms of pyrethroid, carbamate and other pesticide use.
However, their use of organophosphate was significantly different $(\mathrm{p}=0.001$ ), such that about $2 / 3$ of the full-time farmers used organophosphate, while only $1 / 3$ of the part-time farmers used it. Shown in Figure 8 are the brand names of pesticides used by the farmers in the study of $\mathrm{Lu}^{23)}$. Tamaron (methamidophos) was most commonly used by both groups of farmers as shown in the figure above.

In another study of $\mathrm{Lu}^{37)}$, it was found that cutflower farmers used pesticides such as Dithane (mancozeb), Tamaron (methamidophos), and Lannate (methiocarb). Dithane (mancozeb) is the most toxic and hazardous among the pesticides used.

Based on NPCMC data, pyrethroid had been the most frequent cause of pesticide poisoning from 2008 to $2009^{8)}$. Figure 9 shows the frequency of types of pesticides used from the year 2008 to 2009. In the year 2008, there were 112 recorded pesticide poisoning cases due to pyrethroids. Then in 2009,72 cases were recorded. In other countries such as India and Tunisia, organophosphorus and carbamate pesticides were widely used ${ }^{1,39}$.

\section{Pesticide Poisoning Cases according to Age Category}

As for age category, a study showed that more than $60 \%$ of the victims of pesticide poisoning were between 10 and 35 years old ${ }^{34)}$. Based on the records of JP Rizal Memorial Medical Center (1985-1987), 50\% of the pesticide poisoned victims were young adults (22-32 years old) ${ }^{35}$. Records from the Philippine General Hospital showed that early adult (20-35 years old) persons were highly exposed to pesticide poisoning situations (Figure 10) $)^{1)}$.

\section{Pesticide Poisoning Cases in Children and Infants}

Pesticide poisoning is also common among children and infants. In the study of Cucuenco in Benguet province located in the north eastern part of Luzon Island in the Philippines, school children were reported to start working in the vegetable gardens as early as $6-9$ years old ${ }^{40}$. Their work consisted of filling the soil, land preparation, planting, watering, harvesting, and application of both fertilizer and pesticides. The children were familiar with both garden pests and pesticides. Some of them were involved in chemical preparation, mixing, and spraying pesticides. Leftover pesticides were often stored or burned. The symptoms experienced by the children were skin and nasal irritation, headaches, and abdominal pain after use of chemicals. Many of them showed signs of poor nutrition as well as skin rashes. In Nicaragua, records from the Ministry of Health's Pesticide Program showed continuing occupational acute 


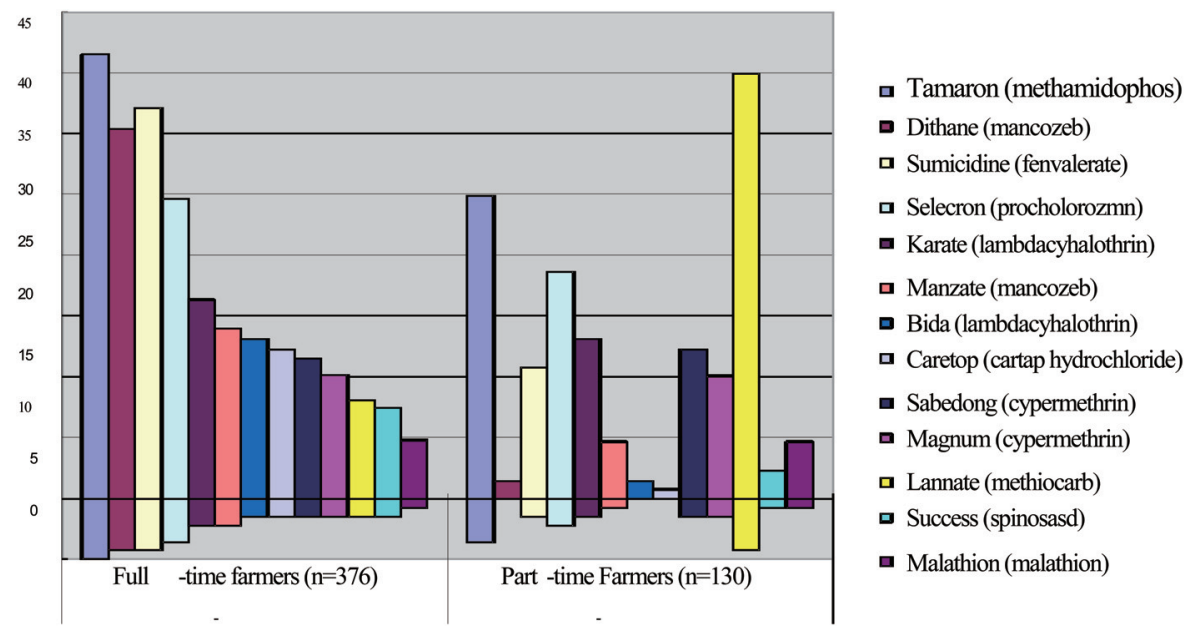

Figure 8 Percentage distribution of pesticides used. Source: $\mathrm{Lu}, 2010^{23)}$.

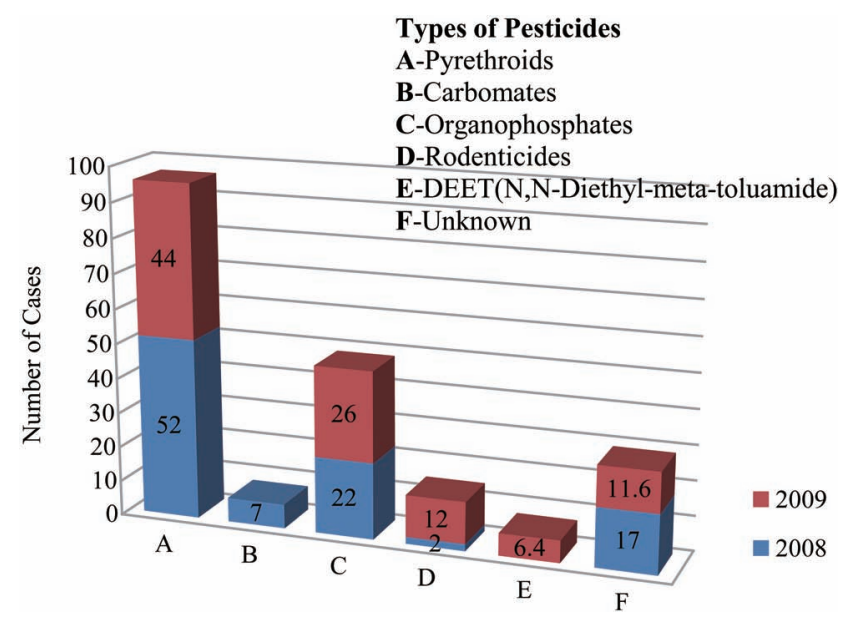

Figure 9 Percentage of types of pesticide poisoning from 20082009, (N=323). Source: NPCM, 2009 ${ }^{8)}$.

pesticide poisonings among children five to 14-year-old. The children were exposed to pesticides at work in tobacco and basic grain crops ${ }^{41)}$. A case study in the United States reported that 2.5-year-old ingested an unknown amount of endosulfan from a 20 -ounce soft drink bottle. Lee et al. also reported a case of pesticide intoxication specifically chlorpyrifos of a healthy 5-year 6-month-old boy ${ }^{28)}$. Moreover, in the study of Lu, pesticide DDT residue such as endosulfan was found in soil. Shown below (Figures 11 and 12) are the pesticide poisoning cases in children and infants admitted to the Philippine General Hospital ${ }^{8)}$.

\section{Pesticide Poisoning Exposure and Practices}

Pesticide self-poisoning is the most common form of suicide in rural Asia, accounting for $60 \%$ of all deaths ${ }^{42)}$. In one study in rural areas of China, highly lethal pesticides are a common method used for suicide ${ }^{43)}$. At the Philippine General Hospital in Metro Manila, Philippines ${ }^{8)}$ (2000-2001), recorded pesticide poisoning cases showed that $80.8 \%$ were intentional in nature.

In Benguet General Hospital in the Philippines, data showed increasing reports of pesticide poisoning among agricultural workers (1987-1989) ${ }^{44)}$. Approximately 30\% were due to accidental poisoning.

In another study, around $88 \%$ of poisoning cases were due to intentional exposure (oral contact in 251 cases), while accidental and occupational exposures accounted for 8 and $4 \%$ respectively ${ }^{34)}$. The most common place of exposure was in the rural home followed by the urban home. Only less than $10 \%$ occurred in the farm.

The National Poison Control and Information Service (2000-2001) data also showed that $87 \%$ of pesticide poisoning cases were intentional in nature with $17.5 \%$ of patients having moderate-severe manifestations ${ }^{8)}$.

One study that was conducted in Barangay Ruparan, Digos City, Davao del Sur, explicitly investigated pesticide exposures/practices among the farmers. This involved pesticide application, storage, and disposal. Most of the respondents worked in the farm sector, and $97 \%$ of the respondents were pesticide applicators. Their activities related to pesticides were as follows: $100 \%$ application in the filed; $100 \%$ washing clothes that have been used when spraying; $100 \%$ mixing pesticides; $99 \%$ re-entry to treated fields;89\% washing equipments; $87 \%$ washing spouses 


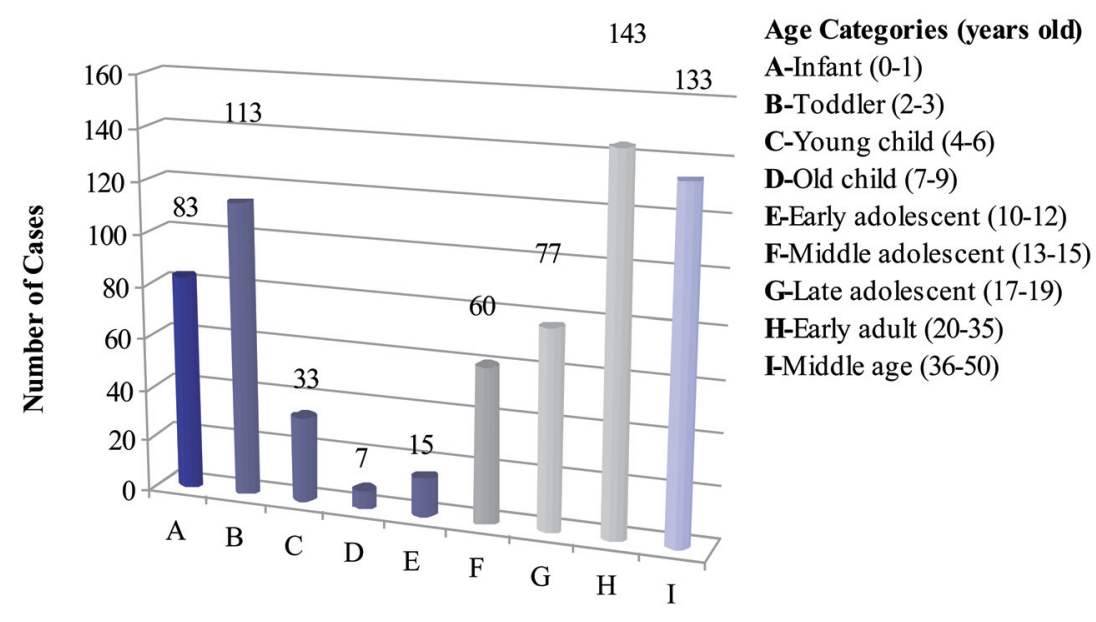

Figure 10 Frequency of poisoning cases at different age category, $(\mathrm{N}=664)$. Source: NPCMC, $2009^{8)}$.

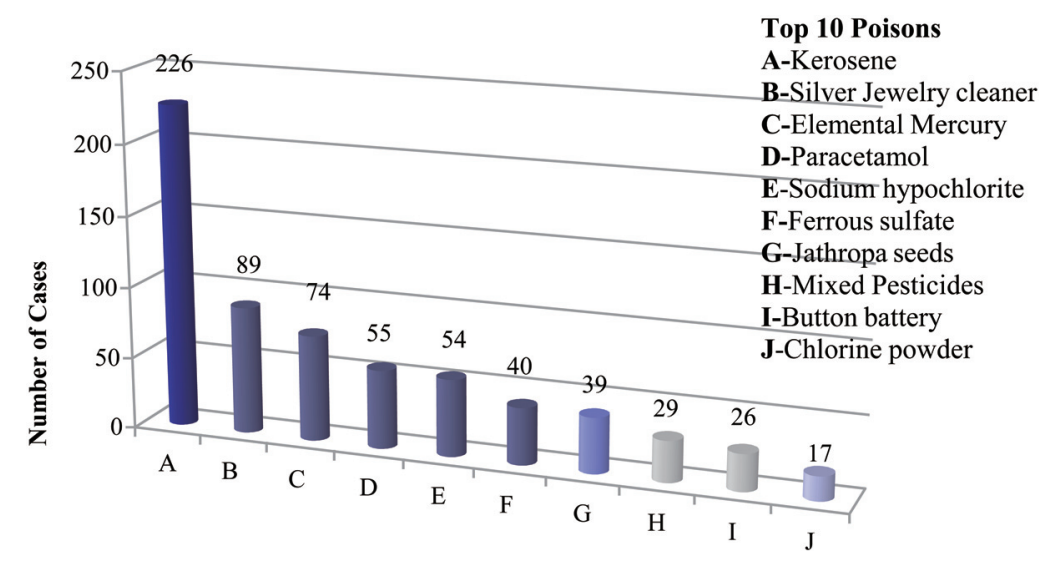

Figure 11 Frequency of top ten poisons including pesticide poisoning cases among children (N=1,832). Source: Philippine General Hospital, 2009).

clothes; $70 \%$ working in fields where pesticides have been used or are being used: $60 \%$ purchasing pesticides. The participants also reported how they were exposed to pesticides, as follows: $98 \%$ exposure to pesticides applied by ground methods; $96 \%$ eating food that is sprayed with pesticides and $4 \%$ water contamination. $94 \%$ of the applicators used protective clothing when applying pesticides and 93\% applicators had washing facilities. Majority of the respondents had experienced spillages which occurred while spraying $(71 \%)$, loading $(5 \%)$, and mixing $(2 \%)$. Majority of the respondents sprayed both with and against the wind. The farmers disposed containers by burying, putting in a trash, burning, or selling. Farm equipment was washed in irrigation canal $(87 \%)$, drum or water container $(5 \%)$, in the field $(4 \%)$, or faucet $(2 \%)$. The farmers stored pesticides at home
(32\%), shed (23\%), or field $(4 \%)^{45)}$.

Other studies have shown that agricultural workers are not using personal protective equipments. The main reason for not using protective measures was discomfort ${ }^{1}$.

\section{Pesticide Poisoning Related Illnesses}

Pesticide exposure has been linked to an increased prevalence of respiratory symptoms in several farming populations. Respiratory hazards significantly contributed to the burden of occupational disease among farmers ${ }^{46}$.

The effects of pesticide exposure can be acute or chronic. Acute toxicity is the effect of a single massive dose which can readily be remedied by medical measures. Non-fatal symptoms include headaches and giddiness as well as skin 


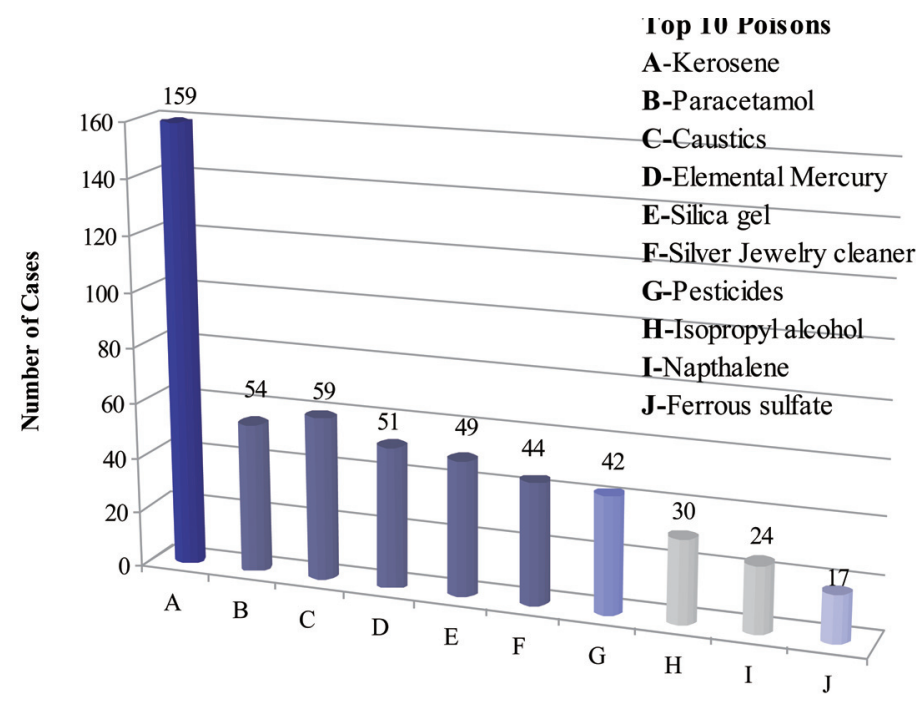

Figure 12 Frequency of top ten poisons including pesticide poisoning cases among infants, $(\mathrm{N}=529)$. Source: NPCMC, $2009^{8)}$.

rashes and skin disorders. Chronic toxicity results from repeated biochemical lesions due to low-level poisoning. This is severely dangerous although physical symptoms may not be present. In chronic cases, it is difficult to determine if the pesticides indeed caused such poisoning ${ }^{47)}$. The Department of Health (2001) found that there were more cases of acute poisoning than chronic ${ }^{48)}$. Both acute and chronic types posed risks to pregnant women ${ }^{49}$.

\section{Recovery of Poisoning Cases including Pesticide Poisoning}

The data from the National Poison Control and Information Service (2000-2001) showed that the average duration of hospital stay in majority of cases was 1-2 days. Shown in Table 4 is the data from Philippine General Hospital (2006) in regard the final outcome of the overall poisoning cases admitted ${ }^{8}$. It is quiet alarming that 44 cases were recorded resulting in death.

\section{Conclusion}

Pesticide poisoning cases in the Philippines have been part of the health problem of the country. In the agricultural sector, pesticides play major role in food production. Unfortunately, overusing pesticides especially without proper equipment and precautionary measures can pose adverse health effects to the farmers and the environment.

It is suggested that the government should implement a limit on the amount of pesticide used by the farmers and
Table 4 Number of cases by final health outcome, 2006

\begin{tabular}{lr}
\hline Final outcome & Cases \\
\hline Full recovery & 939 \\
Full but delayed recovery & 214 \\
Sequelae & 161 \\
Death & 44 \\
Unknown & 562 \\
Total & 1920 \\
\hline \multicolumn{2}{l}{ Philippine General Hospital, 2006 }
\end{tabular}

provide a training program for the farmers regarding proper handling of pesticides. With regards child labor and pesticide exposure, child right's violation should be abolished in both formal employment and in the informal economy. For household use of pesticides, correct information dissemination on proper storage, proper labeling, and correct application should be conducted for urban and rural dwellers. Medical and health personnel in the community health units, and in public and private hospitals should be trained on proper documentation and database keeping of pesticide poisoning cases they handle, as well as on the proper management of pesticide poisoning. Recording should also be done by hospitals on acute and chronic pesticide poisoning including socio-demographics and types of poisoning in order to have more comprehensive data. Government agencies should intensify surveillance and regulation on both household and agricultural pesticides. It 
is further recommended that a more comprehensive database and record keeping be put in place in the various government agencies tasked to monitor and treat pesticide poisoning cases. The state of pesticide-related illnesses mirrors the poor safety practices among farmers as well as lack of necessary supervision from concerned agencies.

\section{References}

1. Singh B, Gupta MK. Pattern of use of personal protective equipments and measures during application of pesticides by agricultural workers in a rural area of Ahmednagar district, India. Indian J Occup Environ Med 2009; 13: 127-130.

2. Library of Congress. Country Profile Philippines, 2006; Available at http://lcweb2.loc.gov/frd/cs/profiles/ Philippines.pdf.

3. Gust E. National profile on occupational safety and health (Philippines). Occupational Safety and Health Center, Manila, 2006.

4. Bureau of Agricultural Statistics, Philippines, 2009.

5. Bass, JK, Ortega, L, Rosales, C, et al. What's being used at home: a household pesticide survey. Am J Public Health 2001; 9:110.

6. Fertilizer and Pesticide Authority, Philippines, 2002; Available at http://www.fadinap.org/philippines/.

7. Rola A. Pesticides, health risks and farm productivity: a Philippine experience. UPLB Agricultural Policy Research Program, Laguna, Philippines, 1989.

8. National Pesticide Control and Management Center, 20042009.

9. Wilson C, Tisdell C. Why farmers continue to use pesticides despite environmental, health and sustainability costs. Ecol Econ 2001; 39: 449-462.

10. Pingali PL, Marquez CL, Palis FG. Pesticides and Philippine rice farmer health: a medical and economic analysis. Am J Agric Econ 1994; 76: 587-592.

11. Loevinsohn ME. Insecticide use and increased mortality in rural Central Luzon, Philippines. Lancet 1987; 1 (8546): 1359-1362.

12. Briones ND. The Philippine croplands ecosystem. In: Report on the national environmental situation: saving the present for the future. U.P. Diliman, Quezon City, 1990.

13. Center for Research and Communication (CRC), Philippine health statistics. Manila, Philippines, 1990.

14. Manigbas GA, Villalobos JG. Pesticide poisoning: a study of cases admitted at J.P. Rizal Memorial Medical Center and DLSU-Medical Center, Dasmarinas Cavite. Med J DLSUEACM 1987; 3: 88-97; Available at http://www.wpro.who.int/ hse/pages/abstract6.html.

15. Philippine General Hospital, 2002 in National Pesticide Control and Management Center, 2004-2009.

16. Cordillera Administrative Region- Occupational Safety and Health Center (CAR-OSHC).

17. Nagami H. Historical perspective of pesticide poisoning in japan and measures taken by the Japanese Association of
Rural Medicine. J Rural Med 2010; 5: 129-133.

18. Tupas J. Pesticide Action Network Philippines, 2006; Available at http://www.cbgnetwork.org/1728.html.

19. Esguerra C. Pesticide, not cyanide, killed pupils in Bohol, DOH Rules, 2005; Available at www.inq.net (http:// news.inq.net/nation/index.phpindex)

20. Philippine Daily Inquirer. Manila, Philippines, 13 March 2005.

21. Palis FG, Flor RJ, Warburton H, et al. Our farmers at risk: behaviour and belief system in pesticide safety. Journal of Public Health 2006; 28: 43-48.

22. Cheng C. Pesticides and Its hazardous effects on the benguet vegetable farmers. J Pak Med Assoc 1994; 69: 169-188.

23. $\mathrm{Lu} \mathrm{J}$. Comparison of pesticide exposure and physical examination, neurological assessment and laboratory findings between full-time and part-time vegetable farmers in the Philippines. Environ Health Prev Med 2009; DOI 10.1007/ s12199-009-0105-x.

24. Whittle B. Communities in Peril: Asian regional report on community monitoring of highly hazardous pesticide use.Pesticide Action Network Asia and the Pacific (PAN AP), 2010; 105-110.

25. Nuguid ZFS, Bautista ERB, Detera SI. Pesticide content of human abdominal fat of Filipinos. Occupational Safety and Health Center.

26. Hu H, Liu X, Jiang F, et al. A novel chemiluminescence assay of organophosphorous pesticide quinalphos residue in vegetable with luminol detection. Chem Cent J 2010; 24:13.

27. Kamanyire R, Karalliedie L. Organophosphate toxicity and occupational exposure. Occup Med 2009; 54: 69-75.

28. Lee JC, Lin KL, Lin JJ, et al. Non-accidental chlorpyrifos poisoning-an unusual cause of profound unconsciousness. Eur J Pediatr 2010; 169: 509-511.

29. EXTOXNET; Available at: http://pmep.cce.cornell.edu/ profiles/extoxnet/carbaryl-dicrotophos/carbaryl-ext.html.

30. Lee JC, Lin KL, Lin JJ, et al. Non-accidental chlorpyrifos poisoning-an unusual cause of profound unconsciousness. Food Additives and Contaminants 2010; 169: 509-511.

31. Arnold D. Pyrethroid Insecticides.Springfiled: Illinois Department of Health. 2007; Available at http:// www.idph.state.il.us/envhealth/factsheets/pyrethroid.htm.

32. Parbhu B, Rodgers G, Sullivan JE. Death in a toddler following endosulfan ingestion. Clin Toxicol 2009; 47: 899901.

33. McCracken JA, Conway GR. Pesticide hazard in the third world: new evidence from the Philippines. Gatekeeper Series No SA1. London: IIED, 1987.

34. Dioquino CC. Report on pesticide poisoning in the Philippines. National Institute of Health and Sciences. 7th GINC meeting. Tokyo, Japan, 2002; Available at:http:// www.nihs.go.jp/GINC/meeting/7th/profile.html

35. Jose P. Rizal Memorial Medical Center, 1985-1987 in Manigbas GA, Villalobos JG. Pesticide poisoning: a study of cases admitted at J.P. Rizal Memorial Medical Center and DLSU-Medical Center, Dasmarinas Cavite. Med J DLSU- 
EACM 1987; 3(2): 88-97; Available at http:// www.wpro.who.int/hse/pages/abstract6.html.

36. General measures in the management of acute pesticide poisoning; Available at http://www.wpro.who.int/hse/pages/ abstract6.html.

37. Lu J. Investigation of pesticide residue in vegetables and occupational safety of farmers in the vegetable industry (unpublished research study). Funded by the Philippine Council for Health Research and Development, DOST, Philippines, 2010.

38. Rother H. Falling through the regulatory cracks: street selling of pesticides and poisoning among urban youth in South Africa. International Journal of Occupational and Environmental Health 2010; 16: 202-213.

39. Food and Agriculture Organization (FAO). Agriculture and Food- Tunisia, Rome 2002; Available online at http:// apps.fao.org.

40. Cucuenco MT. Survey on the health effects of organophosphate exposure among farmers in selected areas of Luzon: a report on the Cordillera administrative region (Car) survey. A paper presented on the 1st DOLE Research Conference held at Occupational Safety and Health Center, Diliman, Quezon City, on 5 December 2001 Available [online]: http://www.ilsdole.gov.ph/PAPs/ResCon/ rcon 01 osh6.htm.

41. Cariols M, Aragon A. Child labor and acute pesticide poisoning in Nicaragua: failure to comply with children's rights. International Journal of Occupational and Environmental Health 2010; 16: 193-200.

42. Tirado R. Agrochemical use in the Philippines and its consequences to the environment. Greenpeace Southeast Asia, 2007; 9.

43. Kong Y, Zhang J. Access to farming pesticides and risk for suicide in Chinese rural young people. Psychiatry Res. 2010 (pubmed abstract).

44. Benguet General Hospital, 1987-1989.

45. Pesticide Action Network (PAN) Asia and the Pacific, 2008.

46. Beseler CL, Stallones L. Pesticide poisoning and respiratory disorders in Colorado farm residents. J Agric Saf Health 2009; 15: 327-334.

47. Magallona E. Pesticide use in the banana and sugar industries. Occupational Health and Safety Center 1984.

48. Department of Health, 2001 National Pesticide Control and Management Center, 2004-2009.

49. Crisostomo L, Molina VV. Pregnancy outcomes among farming households of Nueva Ecija with conventional pesticide use versus integrated pest management. Int J Occup Environ Health 2002; 8: 232-242. 